\title{
The Meaning of Words
}

KEYWORDS: Tranquilizer; aggression; psychogeriatrics; communication

Effective management depends on good communication. This is as relevant in health care as it is in industry, or in governing a nation, or when putting battle plans into effect, or in household management. It is important for people to understand each other's statements. Messages need to be clear and unambiguous.

Problems can arise when a word has several meanings, or when meanings of words change over time. Words may acquire new meanings. How a word is used may differ among populations. A word used innocuously in one country may cause embarrassment if used in another where the basic language is the same. A chat-show host in Australia in about 1980 innocently referred to Muhammad Ali as a boy, and was surprised to discover he had insulted him. Communication may be even more difficult when words need to be translated from one language to another, especially when a word does not have an exact equivalent in the other language.

The name of this journal is International Psychogeriatrics and we belong to the International Psychogeriatric Association. One of the earliest comprehensive books on old-age psychiatry (Pitt, 1982) was titled Psychogeriatrics: An Introduction to the Psychiatry of Old Age. In spite of this imprimatur from leaders of our specialty, the words "psychogeriatric" and "psychogeriatrics" have been misused (Snowdon, 1996). Lobbyists have used the word when seeking funds or attention for people with delirium or challenging behaviors associated with organic brain syndromes. This can indeed be accepted as part of psychogeriatrics, but some administrators (in Australia, anyway) have identified the part as the whole. The next step in some areas has been to separate services and budgets for mentally ill older persons from those for psychogeriatrics! To preserve the unity of such services, it has seemed politic in various parts of the world to refer to our specialty as "old-age psychiatry" or "geriatric psychiatry," even if some prefer to think of themselves as "psychogeriatricians."

"Gay" is the English word that has most obviously taken on an alternative meaning in recent decades, though Ayto (1999) reported that its application to certain sexual attitudes and behaviors has been extant since the 17th century. Further, he stated that "gay" was "largely restricted to the private argot of homosexuals until the mid $1960 \mathrm{~s}$, but from then on it started to 'come out,' and by the 1980s had become a standard English term."

"Schizophrenia" is a term commonly misused by journalists and others. By contrast, misuse of "sexy" to mean 
interesting and exciting (as opposed to sexually attractive) could be seen as humorous and is not necessarily to be condemned. There is a risk that agism will result in "sexy" not being used as a description of interesting and exciting elderly people, or, worse, that Dame Edna Everage will misapply this adjective to poke cruel fun at older persons. (Dame Edna is the alter ego of an Australian comedian, Barry Humphries, who has ridiculed introduction of semantic equivalents-such as "senior citizens" instead of "aged"-aimed at reducing discrimination and increasing respect for certain minority groups).

The word I most want to discuss in this editorial is "tranquilliser" (U.S. spelling, "tranquilizer"), though I shall also refer to "sedative" and "aggressive." According to various dictionaries and encyclopedias, both tranquilizers and sedatives are agents that calm or soothe. A tranquilizer calms a person without affecting clarity of consciousness (Collins English Dictionary, 1998). A sedative lessens nervousness, excitement, or irritation, but will induce sleep if given in large doses. Hypnotics induce sleep. Narcotics depress the central nervous system.

Chloral, paraldehyde, and barbiturates have been available for over a century. Chlorpromazine was first used in 1951, preceding marketing of a variety of other phenothiazine tranquilizers. Nevertheless, in 1957 a new nonphenothiazine tranquilizer, meprobamate, was the most common drug to be prescribed in the United States. It was stated in The Times in 1957 that "the rapidly increasing use of drugs described as tranquillisers has become a cause of concern in many countries" (Ayto, 1999). Chlordiazepoxide (Librium) and diazepam (Valium) were not registered for use until the early 1960 s, but were "notorious as the dependency sedative(s) of the 1960s" (Ayto, 1999).

When learning pharmacology in 1960 as medical students, we were told that the trade name "Largactil" was chosen for chlorpromazine because of its large number of actions. Not only does it tranquilize; it is also antipsychotic and antiemetic. Since that time, phenothiazines, haloperidol, pimozide, and thioxanthenes have tended to be grouped as antipsychotics (or neuroleptics) rather than as tranquilizers. Whether abandonment of the term "tranquilizer" has been engineered by drug companies for marketing purposes or by clinicians for other reasons (e.g., to emphasize differences from benzodiazepines in addictive potential) is difficult to know. For many years, the two groups of tranquilizer were known as major and minor, and were used mainly for treating, respectively, psychoses and neuroses. In 2003, however, young physicians might not recognize the term "major tranquilizer."

Recently published therapeutic guidelines and handbooks listing medications marketed in Australia categorize clozapine, olanzapine, quetiapine, risperidone, and amisulpride among the antipsychotics. Other psychotropic medications are grouped as antidepressants, mood stabilizers, anxiolytics, hypnotics, psychostimulants, and miscellaneous others.

Does it matter that the antipsychotic drugs are no longer referred to as tranquilizers? Maybe. The message conveyed to prescribers and funders is that it is appropriate to prescribe phenothiazines, haloperidol, and atypical neuroleptics for psychosis (hallucinations, delusions) but not for agitation in nonpsychotic cases. In Australia and elsewhere, the 
atypical neuroleptics can be prescribed under the pharmaceutical benefits scheme (PBS) for psychosis but not for agitation or distress. The fact that three major trials (Brodaty et al., 2003; De Deyn et al., 1999; Katz et al., 1999) have shown the effectiveness of risperidone in reducing agitation when associated with dementia, even in the absence of psychosis, without leading to neurological side effects has not yet persuaded funding authorities to allow prescription of risperidone under the PBS. There is other evidence that olanzapine can also be effective in such cases (Street et al., 2000).

Before the emergence of atypical neuroleptics, drugs such as haloperidol were favored in treating disturbed and disturbing behavior among people with dementia. Their effect was modest (Schneider et al., 1990), but surely it related more to reduction of agitation and distress than to suppression of psychotic symptoms?

So-called antipsychotic medications may act mainly as antipsychotic agents in some cases but as tranquilizers (diminishing anxiety and inducing calmness) in others. Indeed, in many cases of schizophrenia the benefits of neuroleptic agents may result more from anxiolytic (tranquilizing) effects than from control of abnormal perceptions or delusions.

Similarly, it should be noted that socalled antidepressants can be effective as anxiolytics (Rickels \& Rynn, 2002), and neuroleptics (e.g., amisulpride) can be effective as antidepressants (Lecrubier et al., 1997).

Aggression is sometimes a manifestation of agitation. Brodaty and colleagues (2003) showed that risperidone is effective in reducing aggressive behavior in cases of dementia, but they did not examine whether the aggressiveness was a manifestation of underlying distress, tension, and anxiety. Observation of cases of dementia with agitation treated with risperidone suggests to me that this medication is tranquilizing in such cases, rather than having a specific action on aggression.

However, it depends what is meant by "aggression"! Volicer and Mahoney (2002) criticized use of the word "aggressive" when describing verbal or physical resistiveness to care by residents with dementia in nursing homes. Talerico and colleagues (2002) expressed similar concerns about language and labeling in the care of older adults with dementia, but noted ethological work that considers aggression as a fighting instinct "generally for the purpose of species preservation." Whereas "aggression" is a term for attacking, offensive, hostile, or destructive actions or attitudes, "aggressive" can mean assertive or vigorous, as well as quarrelsome or belligerent (Collins English Dictionary, 1998). Those who talk of aggressive treatment mean assertive treatment. "Assertive" is preferable. Substituting of the word "assertive" helps eradicate concerns about health staff acting belligerently.

It appears that drug companies shy away from use of the term "tranquilizer." Maybe there is more marketing potential for drugs that affect serotonin levels and thus (they say) reduce aggression (but, with luck, preserve appropriate assertiveness). It seems odd that they do not seek a wider market for so-called antipsychotics by referring to them instead (or also) as nonaddictive tranquilizers. As treatment in younger adults, their most obvious effect is antipsychotic. In cases of dementia and in cases where psychosis 
or other psychological insults have led to distress and agitation, their chief effect is to calm or tranquilize. They are not addictive, but they may cause neurological side effects. Cautious (as opposed to aggressive) use of these tranquilizers is appropriate.

The term "tranquilizer" is accurate and descriptive and should not have been dropped from use.

\section{REFERENCES}

Ayto, J. (1999). Twentieth century words. Oxford, England: Oxford University Press.

Brodaty, H., Ames, D., Snowdon, J., Woodward, M., Kirwan, J., et al. (2003). A randomised placebo-controlled trial of risperidone for the treatment of aggression, agitation and psychosis of dementia. Journal of Clinical Psychiatry, 64, 134-143.

Collins English Dictionary (4th ed.). (1998). Glasgow, Scotland: Harper Collins.

De Deyn, P. P., Rabheru, K., Rasmussen, A., Bocksberger, J. P., Dautzenberg, P. L. J., et al. (1999). A randomised trial of risperidone, placebo, and haloperidol for behavioral symptoms of dementia. Neurology, 53, 946-955.

Katz, I. R., Jeste, D. V., Mintzer, J. E., Clyde, C., Napolitano, J., et al. (1999). Comparison of risperidone and placebo for psychosis and behavioral disturbances associated with dementia: A randomised, double-blind trial. Journal of Clinical Psychiatry, 60, 107-115.

Lecrubier, Y., Boyer, P., Turjanski, S., Rein, W., and the Amisulpride Study Group. (1997). Amisulpride versus imipramine and placebo in dysthymia and major depression. Journal of Affective Disorders, 43, 95-103.

Pitt, B. (1982). Psychogeriatrics (2nd ed.). Edinburgh, Scotland: Churchill Livingstone.

Rickels, K., \& Rynn, M. (2002). Pharma- cotherapy of generalized anxiety disorder. Journal of Clinical Psychiatry, 63(Suppl. 14), 9-16.

Schneider, L. S., Pollock, V. E., \& Lyness, S. A. (1990). A metaanalysis of controlled trials of neuroleptic treatment in dementia. Journal of the American Geriatrics Society, 38, 553-563.

Snowdon, J. (1996). What's in a name-psychogeriatrics? International Journal of Geriatric Psychiatry, 11, 269-270.

Street, J. S., Clark, W. S., Gannon, K. S., Cummings, J. L., Bymaster, F. P., et al. (2000). Olanzapine treatment of psychotic and behavioral symptoms in patients with Alzheimer disease in nursing care facilities. Archives of General Psychiatry, 57, 968-976.

Talerico, K. A., Evans, L. K., \& Strumpf, N. E. (2002). Are nursing home residents with dementia aggressive? Reply. The Gerontologist, $42,876$.

Volicer, L., \& Mahoney, E. (2002). Are nursing home residents with dementia aggressive? The Gerontologist, 42, 875876.

John Snowdon

Clinical Associate Professor

Department of Psychological Medicine University of Sydney Rozelle Hospital Rozelle, Australia

\section{CONFLICT OF INTEREST DECLARATION}

Associate Professor Snowdon is on the Dementia Drug Advisory Board for Janssen-Cilag, Australia. He has been a sponsored speaker and/or investigator for Janssen-Cilag, Eli Lilly, SmithKline Beecham, and Pfizer, and has received financial support to attend educational meetings from Novartis, Roche, and Lundbeck. 